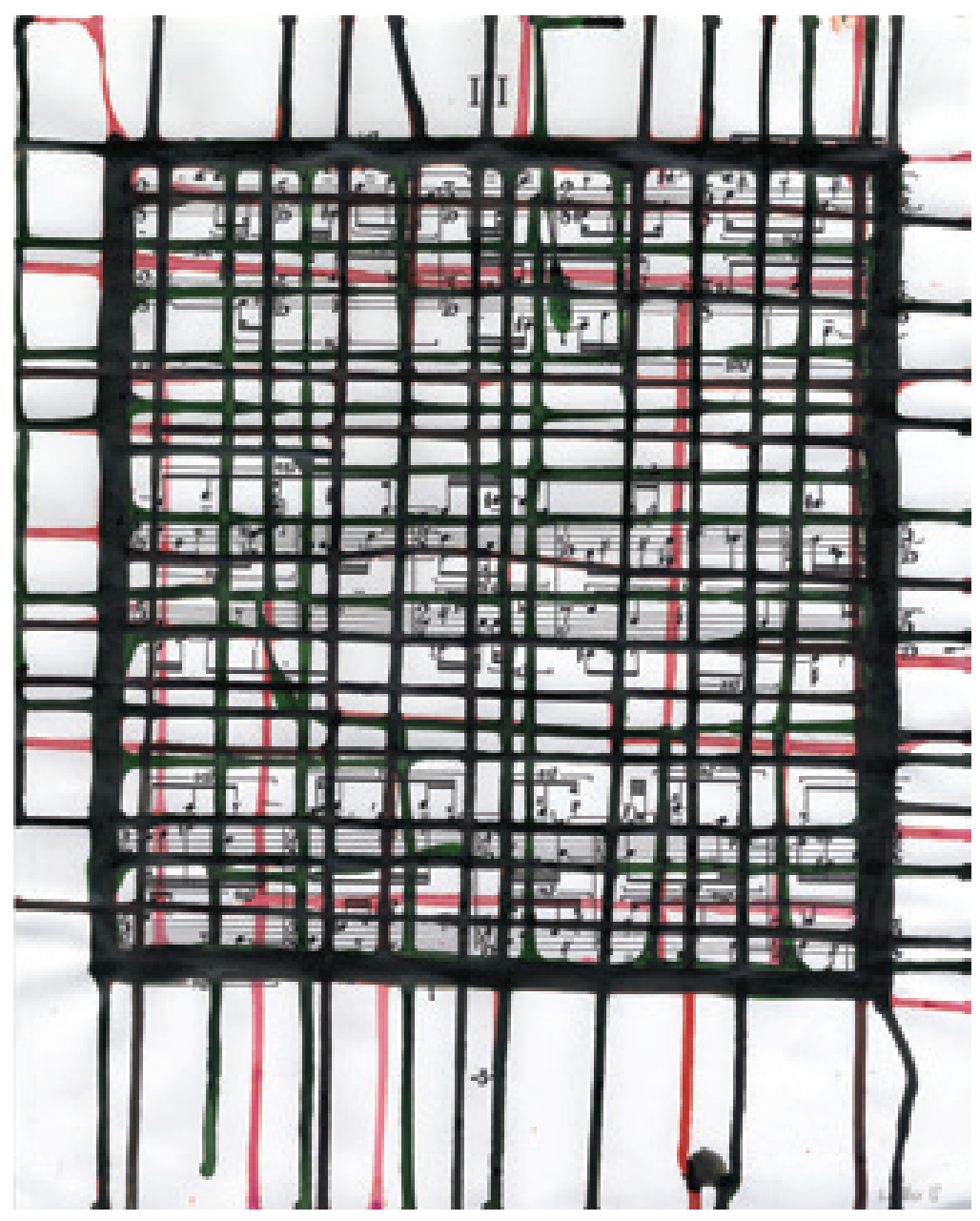

(C) Mike Walker 2013 


\section{Repetitions in extended time: recursive structures and musical temporality}

Bryn Harrison

In an interview published in the Ashgate Research Companion to Experimental Music, Dutch composer Antoine Beuger discusses aspects of repetition and difference in his extended compositions. Astutely, he makes reference to an essay by Deleuze on the work of Beckett. Beuger asks the interviewer James Saunders:

Do you know Deleuze's text about Beckett in which he differentiates exhaustion from fatigue? It's very inspiring. Exhaustion means all the possibilities have been explored, there are no more options left. Fatigue means one doesn't have the (physical) power to continue, even if the exploration hasn't come to an end. (quoted in Saunders 2009, 240)

The reference to Deleuze seems highly apt; Beuger's work, as Saunders suggests, similarly seeks to 'test structures many times to see what they might reveal' $(2009,240)$. In Beuger's works of extended duration, such as the calme étendue series (1996-97) (which can last between 45 and 540 minutes), each sound can be seen to take on its own autonomy, ultimately transcending its repetitious framework to appear as a 'world of singularities, of differences, of ultimate non-repetition' $(2009,240)$. In this chapter I will take a closer look at this subject by examining works that explore the full, exhaustive potentials of musical material through repetitious means. It would be no exaggeration to say that the focus of most of these works illustrate an almost obsessive sense of examining the same object over and over again, often from slightly different angles or perspectives. What I wish to advocate, quoting Hulme, is that 'repetition changes nothing in the object repeated, but does change something in the mind that contemplates it' (quoted in Deleuze 2004, 90). 
Although some of the works under discussion can last for several hours, this is not, as I will argue later, a prerequisite for a work that exhibits a large scale. Alongside the vastness of some of Beuger's piece and the late works of Morton Feldman, I will discuss works of a shorter duration by Kevin Volans and Howard Skempton. These works similarly appear to extend the perceptual timeframe by prolonging rather than varying their materials. It could be said that it is through this process of extension that we come to appreciate the immersive properties of the work. In examining pieces that exhibit a large scale through the repetition of smaller units, I will seek to demonstrate how these recursive structures can, as the British painter Bridget Riley has suggested (Bridget Riley 1979), act as an amplifier in giving significance to passing events. I will also consider the role of memory and question how near and exact repetition can operate in close proximity in providing points of orientation and disorientation for the listener (Harrison 2013). The essay will also draw on three of my own compositions and return in circuitous fashion to the work of Samuel Beckett where, I will argue, repetition not only plays an equally prominent role but to some extent serves a similar operative function to the musical counterparts I will discuss.

However, before discussing these works in more detail I begin with the perceptual challenges of listening itself. Maurice Merleau-Ponty, in his seminal text Phenomenology of Perception, tells us that 'consciousness constitutes time' $(1962,414)$. Merleau-Ponty states that 'we must understand time as the subject and the subject as time' $(1962,422)$. In other words, from a phenomenological point of view, time and being are inseparable; time cannot be intellectualised or understood in an empirical sense since this requires us to objectify time. As Merleau-Ponty reminds us, time cannot be 'seen' anymore than one can see one's own face (423-24). What he asks of us is 'to conceive the subject and time as communicating from within' (410). Much of the music that I find myself drawn to, and will discuss here, is that which seeks to position the listener at the centre of the work and through which meaning is acquired as an emergent property of the experience. The works 
that are being put forward here as examples are those that, I would suggest, construct time not from the 'outside' but from a more experiential standpoint that actively requires the participation of the receptive listener. What this music purports, I feel - as Merleau-Ponty would have us believe - is time as 'subjectivity itself' (422).

However, to place the listener at the centre of the experience, to allow her to bear witness to the present-centredness of the moment, requires a particular sensitivity to dealing with materials. Beuger's calme étendue (spinoza) (1997), with its intimate relationship between sound and silence, is such an example I feel. In its entirety the work consists of the successive reading of all the approximately 40,000 monosyllabic words from Spinoza's Ethics, painstakingly copied in their order of appearance. Each syllable is 'to be spoken in a very relaxed tempo (one word every eight seconds) and with a very quiet voice' (Beuger 2001).

The recorded version of the work $\mathrm{I}$ am listening to ${ }^{1}$ begins with nine minutes of silence, followed by the narration of each monosyllabic word extracted from the Spinoza text, read by Beuger himself. Each event is carefully, clearly and quietly spoken and, as a listener, I am given time to reflect on each syllable as a sound (or as a combined inflexion) rather than as a word conveying its literal meaning. My attention is, at times, drawn to the endings of the sounds (the 's' of 'aus', or the 'ch' of 'durch', for instance) even though no change in pronunciation or emphasis occurs. Each syllable takes place within an eight-second timeframe that might seem highly periodic and yet is of a length that somehow makes it experientially difficult to measure. Each anticipation seems recharged from the last, creating a dynamic equilibrium between that that is (namely sound) and that that is not (namely silence); one might say that a pressure or force exists between words, akin to the surface tension on a still pool of water or the energy of a magnetic field.

1 Edition Wandelweiser Records EWR 0107 (2001). 
After a period of several minutes, a substantially longer silence occurs again. Despite having listened to the extended silence at the start of the work, the absence of the spoken word appears unexpected at first, as if the spoken word is about to make itself audible again but has perhaps, somehow been pushed back in time. Eventually I accept the longer silence that ensues and a vista opens; the work transforms momentarily from a hermetically concealed world to an inclusive, open environment. However, for me, this opening horizon does not provide a place of refuge - it is not merely a space between events but, conversely, an attentive silence that is pregnant with anticipation since there is the strong suggestion that the alternation of syllable, silence, syllable, silence will once more return.

Several minutes later the alternation of sounds and short silences at regular eight second intervals resumes and my feeling is of being carried along on a thermal. Like air drifts, this sense of motion feels as if it is conveyed through something immeasurable; invisible to the eye and yet highly palpable. This eventually seems to give way to what feels like a sense of both sounds and silences becoming omnipresent, despite no actual change having occurred within the alternation of events themselves; I am in both a sounding and a silent space. This is broken by a small but significant occurrence - the incidental repetition of the same syllable through which one is reminded of the role of memory and also of the fact that these syllables are in fact excavations from a buried Spinoza text; these are words that had their origins in a grammatology, held in place through syntactical relationships and that have made a chance occurrence into the 'real world'.

As I continue to listen, the longer silences gain more structural significance. These silences seem spatial; I feel as if I am 'inside' the piece, it seems to be in front of me, behind me, perhaps akin to Merleau-Ponty's 'field of presence' $(1962,415)$. These a-periodic silences can feel long, but how long? One must wait, attentively; these are not pauses or moments of inactivity but moments in which silence feels immanently present. 
Through this alternating structure of sounds that occur every eight seconds and much longer silences, one finds that there almost appears to be two dialectics at play in this work. On the one hand there are the relationships between one sound and the next, and on the other, the relationships between each sound and the short silences that precedes it. As Peter Ablinger has suggested with regard to Beuger's work, it can feel like the silences are the materials of the piece through which the sound events act as pauses or momentary interruptions. ${ }^{2}$ This sense that the hierarchy between sound and silence has seemingly been reversed is highly significant to our sense of time perception in the work, since it suggests something closer to an immeasurable open expanse onto which the periodic events are placed.

Jürg Frey, a Swiss composer closely associated with Beuger and the Wandelweiser group, makes the interesting claim that there is a perceptual form of listening that exists between a more historically-positioned narrative time and time as an open expanse (Frey 2004). In discussing his own music he says: 'I am on the precise threshold where static sonic thinking almost imperceptibly acquires direction, where static, wholly motionless sounds meet the onset of movement and directionality of the sound material' (Frey 2004). What might the 'directionality of the sounding material' be in Beuger's work if the only 'materials' are those of spoken utterances? Perhaps it is that the sounds are successive - we wait in anticipation for the next sound, threatened only by the imminent arrival of a longer pause or the eventual cessation of the work altogether.

This threshold between motion and stasis that Frey speaks of might operate in other ways. In the late works of Morton Feldman for instance, temporal ambiguity is created through the reiteration of self-similar motifs, often within altered or differing contexts. As Dora A. Hanninen has stated:

2 Conversation between Bryn Harrison and Peter Ablinger, 12 March 2013. 
Feldman's late works are characterised by patterns that acquire temporal extension through repetition. Significantly, in late Feldman pattern extension tends to involve not literal extension but semblances of repetition - numerous, often uncoordinated, adjustments in duration, timbre, and pitch. Feldman's penchant for pattern extension by near repetition poses a distinct cognitive challenge: the proliferation of near repetitions frustrates attempts to prioritise events by distinctive features, and thereby to categorise, or even remember, individual instances. The result is a superabundance of nuance that eludes conceptualization, leaves listeners with little to report, analysts with little to say. $(2004,227)$

Feldman himself has talked of 'a conscious attempt at "formalizing" a disorientation of memory' $(2000,137)$, in which he would 'have the same thing come back again, but...just add one note' (quoted in Deforce 2008). This perceptual game, I would suggest, serves to reinforce the intimacy of the work, placing emphasis on the smallest of events despite the considerable length of the overall work. As Feldman has said, 'Scale is no barrier to an intimate art' (quoted in Villars 2006, 80). However, the ways in which this intimacy is created tends to vary according to the works. Below I consider two different examples from Feldman's late period: String Quartet II (1983), which presents a relatively large number of contrasting materials over a highly extended period of time (in some versions up to six hours) and the orchestral work For Samuel Beckett (1987), which, by contrast, can be considered 'monolithic' in its outlook (Paccione 2010) through the ways in which the composer extends a singular temporal module over the course of approximately 55 minutes.

One of Feldman's guiding principles was to work intuitively, which is not to say that no process was used, but rather to suggest that he may, at any point, have broken off into something else. Feldman's longest work, String Quartet II offers an extreme version of this approach through which the listener is required to make continual adjustments to their listening as 
each momentary structure - sometimes of only a few unrepeated bars or sometimes, by extension, of up to several minutes - gives way to another. Magnus Olsen Majmon notes that:

A first reading of the score causes a vague feeling of an enormous number of differentiated structures or fields with a repetitive character. A more profound analysis though reveals a work containing a relatively large, but comprehensible number of fields of differentiated character.' $(2005,4)$

Majmon distinguishes three different field-categories: motifs, chords and patterns. From a purely analytical perspective, Majmon's categorisation is useful and one can easily work up a chart illustrating how the various types of materials recur through the piece, at what proximity and how many times. What this might provide for the analyst is a kind of visual map, a birds-eye view of the work, seen in an instant. However, the perceptual reality - the identity of the piece in which Feldman was most interested - is quite different. What makes the work truly profound for me are the ways in which Feldman makes the experiential aspect of the work render this comprehensible number of fields perceptually impossible. Previously heard events may be repeated exactly but most often contain some slight variation which may or may not be identifiable perceptually without the aid of the score or multiple hearings. These events sometimes occur in relatively close proximity (ie placed on either side of another segment which may, in itself, have been heard previously) or rendered audible again after a period of over an hour. Some events become accumulative and appear almost as themes, whilst others appear only once. (For an experiential account of such an approach, see the final chapter of this book.)

This perceptual terrain is made more complicated by several other factors such as: (i) the material or gestural content of some events being registered more significantly within the memory than others; (ii) the majority of passages being subjected to high but differing levels of repetition (often presented as 
slight variations of repetitions already heard); (iii) the relative degrees of selfsimilarity within the materials themselves (ie an abundance of class 1 and 2 intervals) making the job of discerning one discreet event from another all the more difficult; (iv) the temporal ordering itself through which the characteristics of a segment may be altered through context; and (v) the long duration of the work, which inevitably makes concentration itself an issue.

Yet none of the above can really account for the sheer visceral presence of the material itself. Feldman, it would seem, has the uncanny knack of keeping us alive to the moment. The constant interplay of a four-note pattern, the reiteration of a chord sequence with sudden shifts of dynamics or the seemingly melancholic playing out of a repeated theme against a suspended chord keeps our attention focused on the unfolding of events as they occur. It is not that we find recalling past events difficult but rather that, caught up in the moment, we do not spend the majority of the time concerning ourselves with the act of recall at all. We are only asked to bear witness to a past once it is already manifest in the present moment and then, whilst we try to relate this to the present situation, it has passed, becoming only a memory of a past event.

Through this process - this presence with a trace of the past - we become lost because of the difficulty of remembering. We are forced to resign ourselves to whatever happens next. Like Beuger's calme étendue (spinoza), we submit to the moment. What we bear witness to in Feldman's work is what I have termed a kind of 'diary form'. As with diary entries, some are long, some are short, some are eventful, and others are less so. At times, pages of entirely new material rub up against each other, often contrasting, refreshing and extreme. At other times, the material seems to take on a kind of 'anonymity' (to borrow Feldman's term) in which it seems almost neutral or repetitive to the point of rendering the piece less 'visible'. Each 'entry' is penned in ink by hand and remains uncorrected. There is no editing to the score, no going back over things - they stand as an imprint of a moment in time. As Feldman explains, 'You have to have control of the piece - it requires a heightened kind of 
concentration. Before, my pieces were like objects, now they're like evolving things' (quoted in Rockwell 1999).

Through this constant act of repetition, contrast and renewal, an understanding of part-to-whole relationships within the work becomes redundant. Indeed, the fact that the internal elements are not proportional to one another becomes meaningless. The edges of the canvas, so to speak, are out of sight and the work is viewed as one immersive experience. Musicologist Bob Gilmore has described such an approach as 'overcoming form', stating that, 'in this exploded time-space, questions of form became essentially irrelevant' (2006).

It might be considered that what Feldman offers to the listener instead is a much closer (one might say magnified) perspective of the materials through which we are invited to focus on the subtlest aspects of change. It is not that we peer over the vast chasm presented and see the largeness of the work before us; instead we bear witness to the continual occurrence of small localised events through time. Feldman, I would argue, is not the heroic composer of works of grand proportions but a miniaturist, creating intimate works that often last several hours. Feldman says something similar with regard to the piece For John Cage (1982) 'It's a little piece for piano and violin but it doesn't quit' (quoted in Villars 2006, 131). Feldman is aware of the limitations of memory and the perceptual ambiguities that will ensue. In conversation with Michael Whiticker about String Quartet II, Feldman says, 'I think that the piece is so long because our attention span is so short' (quoted in Villars 2006, 185). It might be said that, as our memories fail us, we lose sight of the larger picture and resolutely focus on the small things. Feldman's success is our failure to comprehend the bigger picture. Faced with the disparity of not really knowing where we are in the work or where we are going simply adds to the abstractness or intangibility of the experience.

Dora A. Hanninen perceptively draws upon the emergent qualities that arise from such an experience. Hanninen uses the notion of emergence to highlight the difficulties of applying traditional analysis to these late works. 
What she stresses is that it is the accumulative aspect which gives meaning to the work and that, being experiential, is not something that can be demonstrated logically by examining the sequential ordering of events (2004, 232). This notion of emergence is particularly pertinent to the chamber orchestra work For Samuel Beckett (1987). In contrast to the highly segmented String Quartet II, what we bear witness to in the orchestral work is the temporal unfolding of one large texture. The immersive quality of the work and its vast sense of scale is something felt, not measured. A proliferation of dyads within the different instrumental groupings produce a hazy interplay of harmonic fields that continually cross like plates of glass placed on top of one other. The harmony is dense, ambiguous and occupies a large range of the spectral field. Any, feeling of it being functionally or teleologically conceived is replaced by slight durational distinctions and changes in orchestration that causes the composite elements of the harmonies to overlap in continually changing ways. Working with a reduced musical pallet, Feldman draws our attention to what is there, keeping us attentive to the subtle nuances of the piece. We may learn to appreciate how what at first may have seemed flat or forbearing is in fact imbued with depth through which registration, timbre and tessitura become elements to behold.

Over time, we start to search the temporal space, looking for relationships between chords or perhaps to the subtle patterning interplay between the harp, piano and vibraphone. Now, as I listen to the piece, I witness the subtlest of interplays between the various pitch ranges. Signifiers such as the different rhythmic placements between the various sections of the chamber orchestra, the particular tessitura of an instrument or the slightest pauses between entries, become more and more pronounced. I am perhaps twenty minutes in and am aware that the pitch patterns that comprise the continual chiming of the harp, piano and vibraphone have inevitably changed but I cannot say how. The interplay between woodwind, brass and strings seems slower and more spacious. Could this simply be the auditory effect of prolonged listening? 
What I am hearing is a constant translation of the same pitches, the continual re-orchestration of the same materials. The dedication to Beckett seems apt; Feldman has spoken of how Beckett would write in English, translate into French and then back into English again. After receiving the text for the opera Neither (1977), Feldman spoke of how he at first found the text incomprehensible and then realised that what Beckett was saying was the same thing over and over again in nuanced ways (quoted in Villars 2006, 194). To return to the Deleuze quotation, there would appear to be the same difference here between exhaustion and fatigue. As I reach the end of For Samuel Beckett I get a sense that, like reading Beckett, all the possibilities have been exhausted through a continual search. The end of the work is not the point at which the materials have become over-tired or outworn, but the point at which renewal seems futile.

As was noted in the introduction to this chapter, the process of extension to create works that yield a greater sense of scale is not exclusively the domain of works that are governed by long durational spans. It is for that reason that other works such as Howard Skempton's string quartet Tendrils (2004) (20') and Kevin Volans's work for two pianos Cicada (1994) (25') might be regarded as exhibiting a large scale despite their comparatively shorter duration. In both of these works the part-to-whole relationships are severely reduced, resulting in work that, for me, seems longer in terms of clock time than what has actually passed.

In Skempton's piece, we bear witness to the continual modulation of 55 canons over a span of some 20 minutes. The material is linearly conceived and modal in content, which gives the impression of a harmonic texture that stretches out in time without recourse to any kind of teleological development. The effect is somewhat like what Jonathan Kramer would have referred to as a 'non-directed linearity', in which a sense of movement is pervasive but at the exclusion of an end-point or goal (Kramer 1988, 61-62). The emergence of melodic lines that seem to arise perpetually from each previous one can be attributed to each modal entry being a minor sixth above the previous 
one, creating the impression, through time, of a piece that is inwardly but continuously mobile. There are small resolutions within the music, but these become once more a point of departure. The impact upon the scale of the work is felt relatively early on. The anticipation of some kind of melodic development occurring within the work is quickly replaced by the sense of a continuum - of a textural interplay, of continuous counterpoint between the four parts of the string quartet. As I listen, now mid-way through Skempton's work, I am aware of an experiential shift. Initially it was the canonic entries that seemed foregrounded, but my attention is now drawn to the countermelodies that Skempton playfully weaves around the continually rising and falling canons. By the end of the work I feel as if my mode of listening has changed considerably but that the music has not really gone anywhere. Again, the transformative experience would seem to come from within rather than from the ways in which the music asserts itself upon us as listeners.

The interlocking of chords in Volans's Cicada for two pianos produces an alteration of dense harmonies that are, for the most part, subject to high levels of repetition. The materials are presented in panels of slightly contrasting length, each of which is preceded by a pause. With the exception of panels that are performed as singular events, these are repeated then replaced in turn by another panel that can be heard as a variation on the one that preceded it. The result is a series of windows onto an array of subtly shifting harmonic patterns. As Adrian Smith has said:

Volans ... seeks to exploit a totally unpredictable shifting in the listener's perceptions. The object in the music, a repeated interlocking pattern, is not subjected to a fixed procedure but instead assumes the role of a highly malleable entity so that its status is continually in a state of flux. (Smith, 2011) 
Perhaps unsurprisingly, Volans cites a visual source as the stimulus for the piece, namely the light sculptures of American minimal artist James Turrell. The similarity is clear; as with viewing one of Turrell's Skyspaces (Smith, 2011) the composer's intention is to draw us into a space for reflection or contemplation, where change is observed gradually and minimally. Smith perceptively describes the emergence of 'inherent rhythms' within the overall perceptual field, which he describes as 'patterns which are not directly played by the performer but which emerge out of the total complex of the music' (2011). As Smith notes, clearly perceptible streams of quavers form in the top voices of each hand whereby notes are not perceived separately but rather as the result of a gestalt sensation (2011). Volans additionally makes slight shifts in tempo and nuanced variation in the dynamic interplay between chords to emphasise these differences. Repetition here serves the function of providing temporal extension, which, in turn, highlights the inherent characteristics of each particular panel.

Finally, I wish to consider issues of temporality and, in particular, the role of repetition in my own works. Dealing with notions of time has been a guiding principle in much of my music since 1995 and has directly affected my approach to structure and the ways in which materials are utilised. Repetition has been integral to this way of thinking, particularly as a device for placing an emphasis upon the experiential aspect of the work. I will focus in particular on three pieces of differing duration - Surface Forms (repeating) (2009) (10’30"), repetitions in extended time (2008) (45') and Vessels (2012/13) (76') - that examine highly recursive structures over differing time scales.

The experiential disparity between a relatively short durational span and a large scale outlined in the Skempton and Volans pieces above is also explored in my composition Surface Forms (repeating) scored for an ensemble of eight players plus soprano voice and tape. Despite the relatively short duration of the work, the high level of textural density, coupled with the seemingly endless self-similarity inherent within the material itself, produces a single block of sound. As I have stated elsewhere, what we hear are: 
...fluttering, ephemeral surfaces that quietly but actively engages the listener in the passing of fleeting events. Successions of notes that operate at a speed beyond that which can be immediately apprehended are repeated again and again, allowing the listener to gradually build up an understanding of the composite elements of the textural surface over an extended period of time. (Harrison 2013).

The pitches are derived from a series of interlocking descending chromatic canons that repeat over and over throughout the piece. These canons are then organised into a metric framework that operates on cycles of 43 seconds. With the return of the cycle, materials may be repeated, altered or replaced with new material.

Whilst preparing this chapter, I am listening to the recording of the piece afresh and am reminded that the textural surface appears so saturated at first that it seems almost impenetrable. Pianist Philip Thomas described the experience to me as rather like climbing a rock face of which we cannot quite get a grasp. ${ }^{3}$ The soprano voice, intoning single syllables, is foregrounded against a bristling backdrop of activity provided by the ensemble. The quiet yet unrelenting surface does not let up - the persistence of the material and the sheer speed and density of the texture provides a kind of continuum through which we witness a tangle of interweaving lines. I am similarly reminded of hearing the piece for the first time during rehearsal with the ELISION ensemble. I remember feeling decisively 'outside' the music for the first few minutes, unable to get a foothold on the events that were quickly passing by. As I continued to listen, my relationship with the surface of the work changed. The voice became less foregrounded and I began to sense direct repetitions embedded within the fabric of the texture. As I listen to the piece now, a descending clarinet motif, identifiable earlier in the piece, is heard again. Am I revisiting the same point in the music or is this motif now heard against a

3 Conversation between Bryn Harrison and Philip Thomas, 27 August 2013. 
different backdrop of changing motifs? Of course, having written the piece, I have perhaps a better understanding from a perceptual perspective, but I am nevertheless surprised how little I feel I recognise within this surface texture. There are, very literally, pages of material that repeat in exactly the same way and yet I rarely hear them as such. The surface is simply too dense and the cycles too long for me to recognise every aspect of the repeated page.

After the work's first performance at the 2009 Huddersfield Contemporary Music Festival, composer Pat Allison perceptively remarked to me that the listening experience for him had been somewhat like skip-reading through a book. ${ }^{4}$ If this imaginary book hypothetically contained exact duplications of pages we would not necessarily recognise them as such since we would most likely be reading a different point on the page. Of course, having heard the piece many times, I now know the piece considerably better - although its inner-complexity still perplexes me. It would seem our memories allow us to recall some of the details of past events but prove insufficient in providing enough of the details to make the experience entirely quantifiable, even if the events taking place are in relatively close proximity.

By contrast, repetitions in extended time, as the title suggests, is conceived over a larger time scale $\left(45^{\prime}\right)$. The music is presented in five closely-related and inter-connected discreet panels, which offer different perspectival views on similar materials. Each panel is played at a slower speed than the last, whilst the degrees of repetitions become progressively greater from one panel to the next. As with Surface Forms (repeating), at first the fleeting passing of events makes the music seem almost out of grasp. As I listen, three distinct layers skirt around each other: streams of constant demisemiquavers in the piano part are pitted against the rhythmic irregularity of the bass clarinet and electric guitar, and freer, oscillating glissandos in the string parts. Against these layers can be felt the pulsating regularity of dense chords played by two

4 Conversation with composer Pat Allison, Huddersfield Contemporary Music Festival, 26 November 2009. 
electric keyboards. Because each panel consists of groupings of instrumental parts that are given their own number of repetitions, what I hear is a latticed textural surface of interlacing loops and circles. The surface, as I listen, appears multi-perspectival, each layer timbrally and rhythmically distinct enough for us to shift our gaze. As the piece moves into the next panel, the texture now transforms into a rhythmic interplay between the clarinet, electric guitar and strings. I become aware of slight alterations in rhythmic placement, crossings and shifting patterns. The rhythmic consistency of the endless streams of demisemiquavers in the piano part can now be perceived as a grid of sorts, an anchor point that helps to highlight the persistent irregularity of the rhythms in the clarinet, electric guitar and string parts.

As the piece progresses I become gradually aware of a reduction in tempo and a spatial dimension emerges. One does not relax but is, perhaps, allowed to ease into the music, the motion becoming more bodily (perhaps akin to breathing). The repetitions increase but I have had time to adjust, to become more immersed in the fabric of the music. Over time the piece becomes more singular, slower and more obsessively repetitious. As I listen to the final panel, the music feels as if it is taking place in slow motion, suspended in time, no longer fleeting. repetitions in extended time, as I see it, is very much about taking the listener to the heart of a sound, magnifying events - creating the embodiment of a living, breathing experiential time. In other words, it requires time to in order to become embodied by time itself.

Of the three pieces of mine under discussion, the encapsulation of a single musical moment extended out over a prolonged time scale is most acutely experienced in my solo piano work Vessels. At over 76 minutes, this work stands as my longest solo work to date. There are no distinct sections, no development of material, no changes of dynamic, just an ongoing impetus of expanding and contracting pitch intervals within a confined registral range; a magnified picture of a self-similar whole. Inspired by the pitch processes used by Skempton in Tendrils, all the material for the piece is similarly constructed from a nine-note Messiaen mode which, as in Tendrils, is 
subjected to its various transpositions. Unlike Skempton's piece, however (in which the material is linearly conceived as a series of canons), Vessels presents simultaneously rising and falling contingent pitches from the mode, which are continually altered registrally through octave transposition. A single cycle of the pitches is encapsulated within just the opening bar of the piece and, in effect, all subsequent bars can be seen as slight modulations and variations of this brief cyclical process. High degrees of repetition of either single bars, groups of bars, or whole pages offer slightly differing perspectival viewpoints on the material.

When listening to the first few minutes of the work I find myself aware of the constant regeneration of pitch patterns, sometimes transposed to related harmonic areas. Repetition appears rife but seemingly never exact. Pitches seem to be constructed from arcs that momentarily cross, appearing almost as small cadential figures that never quite resolve; their point of arrival becomes only a point of departure. The constant near repetition of pitch and rhythm becomes quickly disorientating; a process is discernible but the perceptibility (or perhaps predictability) of the process is intentionally kept slightly out of reach - there are enough possibilities within the process to keep the music in a constant state of flux. As the piece continues, one begins to sense that the music is essentially one tiny moment, examined hundreds of times - a single event stretched out over 76 minutes.

A comparison might be made here with much of Feldman's late music (see my own observations on listening to Feldman's Triadic Memories given in Chapter 5), in which register begins to assume more importance over time. Notes in the highest and lowest registers often appear to gain in significance, becoming transitory points of focus. As I listen to Vessels, I find this is particularly noticeable in passages subjected to particularly high levels of repetition (a three-bar passage repeated seven times for instance), where one is able to dwell on these small events for longer. Similarly, nuanced variations in rhythm acquire greater prominence through reiteration. Extension through the repetition of single units becomes especially significant from a point one 
third of the way into the work where the first 11 pages are repeated and form what would appear from examining the score to be an A/A structure. However, a key difference is that additional repetitions are added or the number of repetitions changed in the repeated pages. For the most part the number of repetitions is considerably increased, which has the affect of more than tripling the length of the piece.

As with Surface Forms (repeating) the literal repetitions of pages are difficult to discern, due to the continual iterations of small localised recursive structures and the high degree of self-similarity within the material itself. In Vessels, these differences are felt more acutely due to the varying degrees of extension through repetition. We can perhaps no longer say that these are the same pages since their identity has been changed. As I write, I am listening to a passage some 50 minutes into the piece. The rhythms are uncharacteristically regular within the context of a work that consists largely of slight deviations in rhythmic proximity. The regularity becomes more persistent by virtue of the high levels of repetition given to the passage. Although the material is a repetition of the same passage presented earlier in the work, its characterisation is transformed into something that sounds new. I feel it is interesting to note that, for the CD of the work, Philip Thomas (to whom the piece is written and dedicated) wished to record the piece in a single take with no further edits. Thomas is intrinsically aware that things change through time, that the subtlest of changes to the way a passage is played will have some performative effect on what immediately follows and that the experiential aspect of time itself will have a significant impact upon how the piece is performed.

An interesting parallel to this work can be seen in Samuel Beckett's short prose work Lessness (English edition 1970). Steven Paton has described how the Lessness uses formal means such as 'exceptionally high levels of repetition and parallelism' $(2009,357)$ to remove a sense of narrative progression from the work. Like Vessels, the second half of Lessness can be seen as a repeat of the first. The text consists of 60 sentences, which are then randomly re- 
ordered and through which 'the forces of successivity - movement in time and narrative progression - [are] replaced by a radical simultaneity in the text' $(2009,357)$. The 'timelessness' to which Beckett's title alludes is inherent within the construction of the work; there is no sense of progress and no sense of 'getting anywhere'. As we read on into the second half of the text we are not directly aware that the sentences are repetitions of the first half as there is nothing to imply a sequence, just a constant set of iterations. As with the aforementioned musical examples there is a feeling of ambiguity to the part-to-whole relations that has a significant bearing on our overall perception of the work. Deleuze's description of exhaustion in Beckett's work is beautifully played out here; Beckett does not stop until every line has been repeated, until every possibility has been exhausted.

Whilst I will resist drawing any immediate conclusions from what has been discussed in this chapter it remains to be said that each of the examples chosen for discussion demonstrates a remarkable propensity for making 'time itself' the subject of the work and through which the immediacy of the moment manifests itself as a living, breathing entity. Kramer makes the crucial point that the present is not simply the place where perception happens but 'it is also the meeting ground of memory and anticipation, both of which colour perception' $(1962,367)$. In other words we find ourselves living both in and through time, constantly engaging with our faculties of memory protention and retention. Time can be seen as both the instant and the accumulation of instants that make up the 'being-time' that we experience. This sensory accumulation of musical events both immediate and more distant, this moment and perhaps the imminent suggestion of what is to come, create an interweaving presence that is both reassuring in its sensorial actuality yet disconcerting in its absence - as soon as I try to give it a name and a place it is gone. 